\title{
ARGUMENTAÇÃo E DEMONSTRAÇÃo EM MATEMÁtICA: A VISÃo DE ALUNOS E PROFESSORES
}

\author{
ARGUMENTATION AND DEMONSTRATION IN MATHEMATICS: THE VISION OF STUDENTS \\ AND TEACHERS \\ ARGUMENTACIÓN Y DEMOSTRACIÓN EN MATEMÁTICA: LA VISIÓN DE ALUMNOS Y \\ PROFESORES
}

João Caldato.

Programa de Pós-Graduação em Ensino de Matemática pela Universidade Federal do Rio de Janeiro (PEMAT/UFRJ). E-mail: joao.caldato.correia@gmail.com

Miriam Cardoso Utsumi.

Programa de Pós-Graduação em Rede - PROFMAT (ICMC/USP) e Docente da Universidade de Campinas (FE/UNICAMP). E-mail: mutsumi@unicamp.br

Lilian Nasser.

Docente do Programa de Pós-Graduação em Ensino de Matemática da Universidade Federal do Rio de Janeiro (PEMAT/UFRJ). E-mail: Inasser.mat@gmail.com

\section{RESUMO}

Com o objetivo de investigar a visão de alunos e professores sobre argumentação e demonstração matemática, à luz da tipologia de provas de Balacheff (1988), aplicamos um questionário a professores da Educação Básica do interior do Estado de São Paulo. A partir da análise dos questionários, selecionamos duas turmas do $9^{\circ}$ ano do Ensino Fundamental, de professores e escolas públicas distintas que resolveram um teste para avaliar o nível de prova desses alunos. Dentre os resultados obtidos, verificou-se que, em geral, os docentes adotam como sinônimos os termos argumentação, explicação e demonstração, e isto é refletido nas resoluções dos discentes, que apresentam o nível de prova classificado como empirismo ingênuo. Acreditamos que os cursos de licenciatura devem proporcionar aos futuros professores a oportunidade de conceber a argumentação e demonstração como um recurso metodológico a ser utilizado em sala de aula, a fim de criar um ambiente favorável à exploração-investigação da matemática.

PALAVRAS-CHAVE: Argumentação. Demonstração. Ensino de Matemática.

\section{ABSTRACT}

The aim of this study is to investigate students' and teachers' vision on argumentation and mathematical proof, on the basis of the theory on kinds of proof created by Balacheff (1988). From the application of a questionnaire with teachers from Basic Education of the interior of the State of São Paulo, two 9-grade classes, from distinct public schools, had been selected. To these groups a test was applied in order to analyze their performance regarding this thematic. Amongst the results obtained, it was verified that, in general, teachers adopt as synonymous the terms argument, explanation and demonstration, which is reflected in the students' resolutions, who present the level classified as naive empiricism The teacher training courses must provide to the future teachers the chance to conceive argumentation and demonstration as a methodological resource to be used in the classroom, in order to create an propitious environment to the exploration-inquiry of mathematics.

KEYWORDS: Argumentation. Proof. Teaching of Mathematics. 


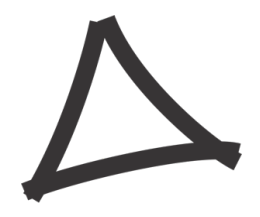

Revista

\section{Triângulo}

Con el objetivo de investigar la visión de alumnos y profesores sobre argumentación y demostración matemática, a la luz de la tipología de pruebas de Balacheff (1988), aplicamos un cuestionario a profesores de la Educación Básica del interior del Estado de São Paulo. A partir del análisis de los cuestionarios, seleccionamos dos salones de clases del $9^{\circ}$ año de la Educación Primaria, de profesores y escuelas públicas distintas que habian contestado a un cuestionario para evaluar el nivel de prueba de esos alumnos. Entre los resultados obtenidos, se verificó que, en general, los docentes adoptan como sinónimos los términos argumentación, explicación y demostración, y esto es reflejado en las resoluciones de los estudiantes, que presentan el nivel de prueba clasificado como empirismo ingenuo. Creemos que los cursos de licenciatura deben proporcionar a los futuros profesores la oportunidad de concebir la argumentación y la demostración como un recurso metodológico que se utilizará en el aula, con el fin de crear un ambiente favorable a la exploración-investigación de las matemáticas.

PALABRAS-CLAVE: Argumentación. Demostración. Enseñanza de Matemáticas.

\section{INTRODUÇÃ̃O}

Este estudo relata uma investigação desenvolvida a partir da observação da ausência de demonstrações nas aulas de Matemática, ao longo da Escola Básica, sob o ponto de vista de alunos e professores. Tal constatação também é feita por Nunes e Almouloud (2013). Resultados cujas justificativas poderiam ser acompanhadas pelos alunos são simplesmente apresentados, com fórmulas prontas, construindo nos alunos uma imagem da Matemática como ciência abstrata e compreendida por poucos. Isso leva à ideia de que há uma relação entre o gosto do aluno pela Matemática e sua interpretação dessa ciência como um conjunto de fórmulas sem sentido.

A investigação recai, portanto, em estabelecer visões de professores e alunos sobre argumentação, provas e demonstração matemática na Escola Básica. O referencial teórico adotado foi a tipologia de provas proposta por Balacheff (1988), que norteou a pesquisa e possibilitou a interpretação dos resultados dos questionários respondidos pelos professores e dos testes aplicados com os alunos.

De acordo com Nasser e Tinoco (2003), após o Movimento da Matemática Moderna houve o abandono total do raciocínio e das demonstrações no ensino na Educação Básica. Segundo as autoras, a maioria das escolas adota um modelo de ensino onde o aluno é levado a resolver extensivas listas de exercícios repetitivos, que para ele não têm significado algum, os quais consistem em aplicações diretas de fórmulas ou na repetição de técnicas apresentadas pelo professor. Elas destacam que o aluno não é questionado ou levado a pensar sobre a resposta do problema, se de fato ela é plausível e coerente com a pergunta, e constatam que "os jovens não estão habituados a pensar e comunicar suas ideias" (p. 1).

Souza (2009) pesquisou argumentação e provas em relação ao conteúdo de Geometria. O trabalho centrou-se na análise de uma questão que solicitava a verificação e a apresentação de uma justificativa dos alunos da Educação Básica para a seguinte afirmação: "Quando se somam os ângulos internos de um quadrilátero qualquer, o resultado é sempre $360^{\circ}$ ". Os resultados da pesquisa evidenciaram que mais de $50 \%$ dos alunos pesquisados classificaram a afirmação da questão como verdadeira, e em relação às justificativas, a 


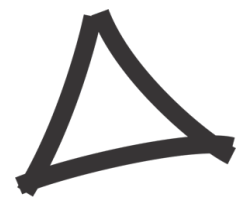

\section{Revista}

\section{Triângulo}

preferência por argumentos empíricos (verificações para alguns casos) se destacou, sendo poucos os que justificaram suas respostas com o uso de propriedades.

Analogamente Ordem (2015) verificou que licenciandos em matemática da Universidade Pedagógica de Moçambique não utilizavam critérios consistentes para avaliar as demonstrações. A pesquisa utilizou conceitos de Geometria Plana para investigar as concepções dos licenciandos sobre argumentação e prova e concluiu que, para os participantes do estudo, argumentação e prova eram simples rituais dissociados de uma de suas funções principais, a de validar ou refutar conjecturas e propriedades.

Avançando nesta temática na formação inicial de professores, Mateus (2015) desenvolveu um estudo com licenciandos da Universidade Federal de Sergipe. A pesquisa investigou se sequências de atividades que exploravam provas sob os pontos de vista didático e curricular poderiam favorecer a ressignificação da importância do processo de ensino de conceitos e atitudes concernentes a esse tema por futuros professores. Os resultados mostraram que os licenciandos passaram a adotar um sentido mais amplo para as provas, admitindo substituir a reprodução das demonstrações presentes nos livros pelo fazer matemática, incluindo experimentações, argumentações, conjecturas e, quando fosse necessário, provas rigorosas.

Tais resultados são importantes, pois alguns estudos mostram que os alunos explicitam melhor seus argumentos matemáticos quando são colocados em contato com atividades, currículo e professor preparados para a construção desta habilidade. Entretanto, como observado por Aguilar Júnior (2012) o curso de formação inicial não prepara o professor para o ensino-aprendizagem da argumentação matemática em sua prática.

Aparentemente a demonstração na licenciatura não consiste num objeto de estudo, mas se limita a uma mera ferramenta para os licenciandos, isto quando numa disciplina de conteúdo específico algum resultado é demonstrado pelo professor.

Para Garnica, a demonstração seria

[...] fundamental nos cursos de formação de professores, não como mero recurso técnico, mas numa abordagem crítica, que possibilitasse uma visada panorâmica nos modos de produção e manutenção da "ideologia da certeza" para que, a partir disso, pudessem ser produzidas formas alternativas de tratamento às argumentações sobre os objetos matemáticos em salas de aula reais (GARNICA, 2002, p. 4).

Pietropaolo (2005) também defende o uso de demonstração nos cursos de formação inicial sob uma perspectiva mais ampla. Para ele, as provas não devem ser utilizadas somente para a compreensão da Matemática, mas sim para refletir a "evolução" do pensamento matemático por meio de uma perspectiva didática, curricular e histórica.

Acreditamos que nesta perspectiva o futuro professor teria condições de inserir a prática da argumentação em matemática, na Escola Básica, em qualquer bloco de conteúdos, 


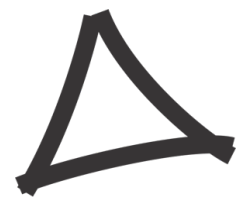

\section{Revista}

\section{Triângulo}

seja Aritmética, Álgebra ou Geometria. Concordamos com Nunes e Almouloud (2013) que acreditam que "o que se busca com essa prática [de desenvolver a argumentação e prova nas aulas de matemática] é que os alunos, a partir de procedimentos empíricos ou não, possam refletir e conjecturar por intuição, observação, analogias, experimentação, etc.” (p. 153).

Destarte essas considerações, apresentamos um estudo que investigou o nível de prova de alunos e o entendimento de professores sobre os conceitos de argumentação e demonstração matemática.

\section{REFERENCIAL TEÓRICO}

Balacheff (1988) desenvolveu uma pesquisa com estudantes franceses, por meio do estudo de propriedades geométricas dos polígonos e através da análise de dados elaborou uma tipologia de provas organizadas em provas pragmáticas e provas intelectuais.

As provas pragmáticas baseiam-se na verificação empírica para justificativa de propriedades e regularidades, ou seja, através da observação, exemplos, desenhos, as quais Vergnaud (1981 apud BALACHEFF, 1988, p. 217) define como "recursos de ação". Já as provas conceituais, não usufruem destes recursos e são caracterizadas pela linguagem matemática baseadas na argumentação e em teorias que permitem a validação de uma propriedade, não se limitando a meras constatações numéricas.

Para melhor delinear a tipologia de provas, a partir da classificação anterior, Balacheff (1988) determina quatro níveis considerando os raciocínios e conhecimentos apresentados ao elaborar uma prova: empirismo ingênuo, experiência crucial, exemplo genérico e experiência mental.

O empirismo ingênuo é baseado na observação, onde o aluno assume como verdade a conjectura de um enunciado através da verificação de poucos e simples casos, sem questionamento algum quanto às suas peculiaridades. Na experiência crucial verifica-se a realização de um experimento particular, para afirmar a verdade de uma proposição. A principal diferença com o anterior é a evidência de generalização, a qual se dá pela realização de experiências, na busca de um resultado geral. No exemplo genérico, a validação ocorre tomando-se um representante da classe de objetos para explicar a validação de uma proposição. O objetivo é deduzir as características que representam esta classe, além de explicitar as razões que validam a propriedade, as quais são concluídas a partir da manipulação. A experiência mental baseia-se no raciocínio lógico-dedutivo para garantir a veracidade de uma propriedade de forma genérica, em que "a validação de uma proposição é sustentada pela teoria" (BALACHEFF, 1988, p. 56) e não por exemplos ou casos particulares.

O empirismo ingênuo e a experiência crucial estão enquadrados na prova pragmática, enquanto a experiência mental na prova intelectual. Já o exemplo genérico evidencia a 


\section{$\Delta$}

\section{Revista}

\section{Triângulo}

transição entre os dois tipos de provas, dado que "consiste na explicitação das razões que validam uma propriedade que encerra uma generalidade mesmo, fazendo uso de um representante particular" (GRAVINA, 2001, p. 67).

Para o desenvolvimento do trabalho, utilizamos as seguintes definições apresentadas por Balacheff:

Chamamos de explicação o discurso que visa tornar compreensível o caráter de verdade, apresentado pelo locutor, de uma proposição ou de um resultado. As razões podem ser discutidas, recusadas ou aceitas.

Chamamos prova uma explicação aceita por certa comunidade num determinado momento. Esta decisão pode ser objeto de um debate em que o significado é a exigência de determinar um sistema de validação comum aos interlocutores.

No contexto da comunidade matemática, apenas as explicações que adotam uma forma particular podem ser aceitas como provas. Elas são uma sequência de enunciados seguindo regras determinadas: um enunciado é conhecido como verdadeiro, ou é deduzido daqueles que o precedem por meio de uma regra de dedução tomada num conjunto bem definido de regras. Chamamos essas provas de demonstração. (BALACHEFF, 1987, p.147-148, tradução nossa).

Observamos, contudo, que no âmbito da matemática, em geral, uma prova é equivalente a uma demonstração.

\section{MATERIAIS E MÉTODOS}

\subsection{Participantes}

Participaram da pesquisa 13 professores de Matemática do Ensino Fundamental e os alunos de duas turmas de $9^{\circ}$ ano do Ensino Fundamental.

A escolha do grupo de professores foi por conveniência, devido à facilidade e acessibilidade para pesquisá-los. Entretanto, ressaltamos a diversidade da amostra dos professores quanto à sua formação e localização, pois os 13 educadores que contribuíram com a pesquisa estão distribuídos em 6 escolas de Educação Básica distintas, sendo 4 instituições públicas e 2 particulares, pertencentes a 4 cidades diferentes do interior do Estado de São Paulo. A notação utilizada para designar os professores será a letra maiúscula $\mathrm{P}$, seguida do número de 1 a 13 , referente ao docente.

A seleção do grupo de alunos foi intencional, pois ao analisarmos os questionários dos professores participantes, foram escolhidos dois docentes, que apresentavam concepções divergentes sobre argumentação e demonstração em sala de aula. Tal escolha foi feita para analisarmos o nível de prova que apresenta uma turma em que o professor supostamente utiliza como metodologia de ensino a argumentação matemática e outra em que o docente não faz uso dessa abordagem. 


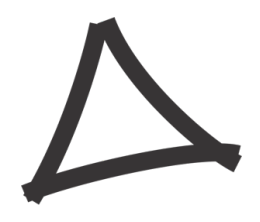

Revista

Triângulo

Os docentes escolhidos foram os professores P8 e P2. O P8 afirmou que considera importante e faz uso da argumentação e demonstração em sala de aula, pois "traz independência matemática aos docentes, bem como liberdade ao debate e autoconfiança" aos alunos. Quanto às dificuldades de utilizar este recurso metodológico em aula, o docente declarou que "não há dificuldades nesta dinâmica".

Já o P2 afirmou que usa “muito pouco demonstração de fórmulas em sala de aula”, e diferentemente do P8, evidenciou uma série de fatores que dificultam a utilização deste recurso em sala: "Quando se utiliza desse recurso o desinteresse é muito grande, o nível de aprendizagem, pré-requisitos estão a cada ano, mais baixos...”, e concluiu que, apesar da importância da demonstração no ensino de matemática, "é necessário o resgate de alguns valores que estão sendo perdidos (...) para aí sim avançarmos e de fato darmos uma aula como deve ser dada".

Escolhemos para a aplicação dos testes os alunos do $9^{\circ}$ ano do Ensino Fundamental desses professores que são de duas escolas públicas distintas, sendo uma turma com 33 alunos do professor P8, designada por turma A e uma turma com 28 alunos do professor P2, designada por $\mathrm{B}$.

Ao todo 61 estudantes de 13 a 15 anos de idade participaram deste estudo. A notação utilizada para designar o aluno da turma A será a letra maiúscula $\mathrm{A}$, precedida do número de 1 a 33, referente ao discente. Analogamente, para os alunos da turma B.

\subsection{Instrumentos}

Para analisar os entendimentos e as experiências em sala de aula desses professores sobre argumentações, provas e demonstrações, elaboramos um questionário e para analisar as resoluções dos alunos, montamos um teste matemático. A seguir, descrevemos cada instrumento de análise e os processos de aplicação.

O questionário dos docentes estruturava-se em quatro páginas e continha 12 perguntas. As questões de 1 a 4 diziam respeito ao ambiente de trabalho do professor. De 5 a 8 , sobre a sua formação e as perguntas de 9 a 12 eram dissertativas, as quais almejavam saber se houve estímulo à prática do recurso metodológico voltado ao ensino-aprendizagem da argumentação matemática durante a sua formação, se o professor a utilizava em sala de aula, o relato de experiências vivenciadas ou dificuldades encontradas ao utilizá-la e a importância desse recurso metodológico na formação dos alunos. Esse questionário foi entregue aos 13 professores.

O contato e a entrega dos questionários aos docentes ocorreram predominantemente de forma online, e para alguns professores a entrega foi feita na instituição em que lecionavam, fora do horário de aula.

O teste dos alunos era composto por 4 questões matemáticas, além de 2 perguntas que 


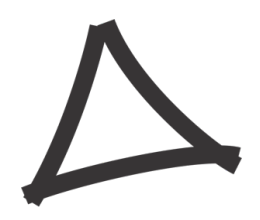

Revista

\section{Triângulo}

tinham por objetivo investigar a existência de relação entre o gosto discente pela matemática e a compreensão dessa ciência como um conjunto de fórmulas sem sentido. A questão 3 foi o primeiro exercício teórico, no qual os alunos deveriam verificar e demonstrar a seguinte afirmação: "A soma de dois números ímpares é sempre igual a um número par". O problema possuía uma abordagem algébrica, onde a melhor resposta esperada era que o aluno conseguisse escrever, de forma genérica e algébrica, a representação de dois números ímpares e concluir que a soma é sempre um número par, ou seja, da forma $2 \mathrm{k}$, onde $\mathrm{k} \in \mathbb{Z}$. Entendemos por "melhor resposta" aquela em que o aluno é capaz de desenvolver a questão no nível da experiência mental, conforme proposto por Balacheff (1988).

Já a questão 4 possuía uma abordagem geométrica sobre o número de diagonais de um polígono convexo. No item (a) era preciso verificar que o pentágono convexo ilustrado no enunciado possuía 5 diagonais. $\mathrm{O}$ item (b), sem qualquer ilustração, solicitava o número de diagonais de um hexágono convexo. E com base nos itens anteriores, no item (c) era esperado que o aluno conseguisse generalizar esse raciocínio e concluir que a expressão para o cálculo do número de diagonais de um polígono convexo de $\mathrm{n}$ lados é dada por $\frac{\mathrm{n}(\mathrm{n}-3)}{2}$. Nesta questão, a nossa hipótese era de que os alunos, baseados na resposta do item (a), concluiriam que o hexágono convexo possui 6 diagonais e erroneamente generalizariam o raciocínio de que, o número de diagonais em um polígono convexo é igual ao número de lados.

A questão 5, que não será abordada neste artigo por falta de espaço, foi adaptada da prova da $2^{\text {a }}$ fase - Nível 2 da $9^{\text {a }}$ Olimpíada Brasileira de Matemática das Escolas Públicas (OBMEP) do ano de 2013 e relacionava o conceito de divisibilidade com a fatoração em números primos.

Por fim, a questão 6 foi retirada e adaptada do teste aplicado na pesquisa de Souza (2009). O problema apresenta duas respostas, dos alunos Amanda e Breno, à solicitação do professor para demonstrarem a seguinte afirmação: "Quando você soma as medidas dos ângulos internos de um triângulo qualquer, o resultado é sempre $180^{\circ}$." A resposta de Amanda enquadra-se no nível de prova pragmática, enquanto a de Breno no nível de prova intelectual. Assim, foi solicitado que o aluno desse uma nota para ambas as respostas e as justificassem, a fim de analisar qual a visão dos alunos sobre o termo "demonstração".

A aplicação do teste ocorreu em uma hora-aula (50 minutos) pelo próprio pesquisador, acompanhado pelo professor de matemática da turma, porém antes da realização do teste, todas as questões propostas foram explicadas aos estudantes.

\section{ANÁLISE DOS DADOS E RESULTADOS}

\subsection{A visão dos professores}




\section{$\Delta$}

\section{Revista}

\section{Triângulo}

Ao analisar os questionários respondidos pelos 13 professores de matemática da Educação Básica, constatamos que as variáveis referentes ao ambiente de trabalho não influenciaram nas respostas sobre argumentações e demonstrações em matemática.

Os participantes da pesquisa eram, em maioria, docentes na rede estadual de ensino, e lecionavam em todos os anos, desde o $6^{\circ}$ ano do Ensino Fundamental até a $3^{\mathrm{a}}$ série do Ensino Médio. Ao analisar qualitativamente os questionários, notamos que a variável referente ao nível escolar de atuação do professor também não influenciou em suas respostas. Inicialmente imaginávamos que os professores atuantes no Ensino Médio poderiam dissertar com maior propriedade sobre a argumentação matemática, visto que atuam com um público mais maduro, com um conteúdo matemático mais complexo, com uma quantidade maior de fórmulas e expressões, as quais poderiam ser fonte de questionamentos dos alunos, constituindo-se em oportunidades para trabalhar com a argumentação como metodologia de ensino. Tal conjectura não foi confirmada.

Quanto à formação dos participantes, houve um equilíbrio em relação aos que cursaram a graduação em instituição pública ou particular. O mesmo aconteceu em relação à formação continuada: o número de professores que cursaram ou estavam cursando pósgraduação era semelhante ao número dos que não possuíam pós-graduação.

No entanto, ao analisar as informações referentes à formação dos professores e suas compreensões sobre argumentação e demonstração, verificamos que, no grupo investigado, os docentes com maior familiaridade e conhecimento sobre o assunto haviam cursado a graduação em instituições públicas. Além disto, dentre esses, três docentes estavam cursando ou cursaram o Mestrado Profissional.

Acreditamos que esta relação se deve ao fato de que, nas universidades públicas, os cursos de licenciatura dão mais ênfase ao ensino da matemática acadêmica, o qual se estrutura com o uso recorrente dos termos definição, axiomas, proposição, teorema, demonstração, corolário, etc. e, consequentemente, os egressos dessas instituições teriam mais condições de diferenciar com maior domínio os termos adotados em nosso estudo.

Nove professores afirmaram que durante a sua formação houve estímulo à prática voltada ao ensino-aprendizagem de prova/demonstração matemática. Os demais responderam que houve parcialmente. No entanto, apesar deste número significativo, observou-se que, para seis professores, aproximadamente metade da amostra, os termos argumentação, explicação e demonstração eram assimilados como sinônimos em sala de aula.

A professora P11 afirmou que fazia uso do recurso metodológico voltado ao ensinoaprendizagem da argumentação matemática em sala de aula, pois "se o aluno entender $o$ conceito passado, de onde saiu tal resultado, tal fórmula, ele irá fixar a habilidade, diferente de apenas decorar algo". No entanto, ao exemplificar uma experiência desenvolvida, relatou sobre a possibilidade de "mostrar o volume de um sólido, utilizando cones, cubos, cilindros para mostrar o tanto de água que cabe neles (...), que mostra a sua veracidade”. \begin{tabular}{l|l|l|l|l|l|l|} 
(C) Rev. Triang. & Uberaba, MG & v. 10 & n. 2 & p.74-93 & Jul.-Dez. 2017 & ISSN 2175-1609 \\
\hline
\end{tabular} 


\section{$\Delta$}

\section{Revista}

\section{Triângulo}

Aparentemente, na visão da professora, o fato de verificar empiricamente um simples caso, seria suficiente para demonstrar o resultado. Porém, segundo a tipologia de provas, o caso descrito consiste numa experiência crucial, não caracterizando uma demonstração.

A professora P9 também afirmou utilizar esse recurso metodológico em suas aulas, e citou como exemplo o que ela chamou de "demonstração prática do Teorema de Pitágoras", conforme se segue:

"Foi pedido ao aluno a construção (em cartolina) de um triângulo retângulo, em seguida foi pedida a construção de 3 quadrados de medidas de lados iguais aos lados do referido triangulo retângulo. Calcula-se as áreas dos 3 quadrados e comprova-se que a soma das áreas dos 2 quadrados menores coincide com a área do quadrado maior, demonstrando na prática o Teorema de Pitágoras".

Novamente, consiste num caso de experiência crucial, e o que ocorre de fato é uma explicação da fórmula, segundo a definição proposta por Balacheff (1987).

Os dois exemplos constituem provas pragmáticas, o que indica que esses professores devem considerar esse tipo de justificava/verificação como provas matemáticas.

Entretanto, houve algumas exceções como, por exemplo, o professor P6, que afirma não fazer uso de demonstrações em sala de aula, mas sim de justificativas, conforme escreve:

"A demonstração com o rigor e formalismo que a matemática pede nunca foi trabalhada por mim em sala de aula. O que faço é uma justificativa, tendo como objetivo mostrar ao aluno o desenvolvimento de alguns resultados, além de buscar uma apresentação estruturada, não ficando somente na apresentação de resultados".

De modo semelhante, o professor P13 ao relatar sua experiência em sala de aula, sobre a soma dos ângulos internos do triângulo, evidenciou que procura "apenas justificar as propriedades com o uso de colagens", e não demonstrá-las. Outro exemplo é o professor P3, o qual afirmou que argumenta e/ou justifica os resultados matemáticos, ações que ele denotou como "elementos facilitadores do aprendizado", e que em sua concepção, era uma forma “alternativa ao formalismo da demonstração matemática”. É importante ressaltar que os três professores possuem formação acadêmica em instituições públicas e estavam cursando ou cursaram o Mestrado Profissional.

Outra concepção que apareceu durante a investigação foi a de que o uso da argumentação e demonstração matemática em sala de aula depende das características da turma, tais como: grau de abstração e generalização, conhecimentos prévios e vontade por aprender algo novo. Caso contrário, ao utilizá-la o professor inconscientemente poderá comprometer a aprendizagem dos alunos, como explicou a professora P1:

"Acredito que o professor deve conhecer muito bem cada turma para delimitar até onde é possível chegar com cada uma, pois uma turma pode estar pronta para receber esse tipo de informação (mais formal, mais 


\section{$\Delta$}

\section{Revista}

\section{Triângulo}

rebuscada) e outra pode ser que nem esteja conseguindo fazer o básico, tão pouco entenderá uma demonstração. Acho que depende muito da turma e da intenção do professor: uma demonstração pode assustar os alunos que já possuem dificuldades e desestimular seu aprendizado".

De modo geral, os professores afirmaram que é importante para a formação do aluno que o professor argumente e/ou demonstre os resultados matemáticos, pois "tanto a escola quanto o educador têm o papel de formar alunos críticos e conscientes", conforme descreveu a professora P12, representando o ponto de vista de outros docentes.

Entretanto, alguns professores que consideraram importante o uso de argumentação e/ou demonstrações para a formação dos alunos, salientaram algumas dificuldades para o uso deste recurso metodológico nos tempos atuais.

O professor P2, por exemplo, relatou suas percepções ao longo dos seus 23 anos de carreira, ao citar outros desafios que considera maiores no ensino de matemática: ter o comprometimento do aluno em sala de aula; resgatar alguns valores que se perderam nos últimos tempos, como a necessidade de que as famílias sejam compromissadas efetivamente na educação dos seus filhos, a fim de que os alunos valorizem e deem importância aos estudos. Na sua visão, partindo disso, seria possível o avanço na Educação e lecionar uma aula com recursos à argumentação e à demonstração matemática.

A professora P5 pareceu se mostrar mais resistente ainda, ao afirmar que a constante mudança no sistema educacional tem influenciado negativamente o interesse do aluno e, consequentemente, desestimula o uso desta e de outras metodologias de ensino.

\subsection{O nível de prova dos alunos}

Com base na análise quantitativa, ao comparar os indicadores das turmas A e B, sobre o gosto pela matemática e sua visão enquanto ciência, notamos que eles convergiam para o mesmo resultado e por isso analisamos as frequências das respostas de ambas as turmas em conjunto.

Dos 15 alunos (aproximadamente 24,6\%) que afirmaram não gostar de matemática, seis responderam que a matemática limita-se a memorizar um conjunto de fórmulas sem sentido. Dos 12 alunos (aproximadamente 19,7\%) que disseram que a matemática se resume a decorar um conjunto de fórmulas sem sentido, cinco afirmaram que não gostam dela. $\mathrm{Ou}$ seja, dentre esses 12 estudantes, curiosamente sete manifestaram gostar da matemática, mesmo acreditando que ela se resume a uma coleção de expressões sem nexo.

Esses resultados parecem indicar que, contrariamente à nossa hipótese inicial, apenas uma parte dos alunos que afirmaram não gostar de Matemática acredita que esta se resume a um conjunto de expressões sem nexo. Tais alunos que apresentam fortes resistências e dificuldades em aprender matemática, talvez pudessem se beneficiar do uso de outras metodologias. Logo, além da utilização do recurso metodológico voltado ao ensino-

\begin{tabular}{l|l|l|l|l|l|l|} 
(C) Rev. Triang. & Uberaba, MG & v. 10 & n. 2 & p.74-93 & Jul.-Dez. 2017 & ISSN 2175-1609
\end{tabular}




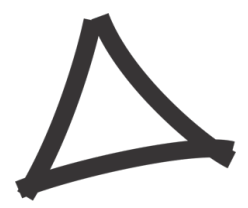

\section{Revista}

\section{Triângulo}

aprendizagem da argumentação matemática em sala de aula, o professor deveria conhecer e dominar outras metodologias de ensino como, por exemplo, o recurso à história da matemática, à resolução de problemas, ao uso de tecnologia e de jogos, entre outros.

Na questão 3 foi indagado se a afirmação "a soma de dois números ímpares é sempre igual a um número par" era verdadeira e solicitada a sua demonstração.

Ao analisar os testes da turma A, verificamos que 25 alunos responderam corretamente, que a sentença era verdadeira, seis responderam que era falsa e dois alunos não fizeram. Já na turma B, 25 alunos afirmaram que a sentença era verdadeira, dois responderam que era falsa e um aluno não fez. Observamos que a ampla maioria conseguiu entender e avaliar corretamente a sentença.

Com relação à justificativa dos alunos que responderam corretamente, a tabela 1 destaca os tipos de demonstrações realizadas:

Tabela 1 - Distribuição das respostas dos alunos das turmas A e B que responderam corretamente à questão 3

\begin{tabular}{ccc}
\hline Resposta & Turma A & Turma B \\
\hline Empirismo ingênuo & 13 & 12 \\
Experiência crucial & - & 2 \\
Exemplo genérico & - & 1 \\
Repetição da afirmativa & 4 & 7 \\
Justificativa incorreta & 4 & - \\
Sem justificativa & 4 & 3 \\
\hline Total & $\mathbf{2 5}$ & $\mathbf{2 5}$ \\
\hline
\end{tabular}

Fonte: Autoria própria.

Observamos que a maior parte dos alunos argumentou que a sentença era verdadeira através de um ou poucos exemplos numéricos, que segundo a tipologia de provas de Balacheff (1988), é definido como empirismo ingênuo, o primeiro nível ao elaborar uma prova. A figura 1, que consiste na resposta apresentada pelo aluno 27A, ilustra esta categoria:

Figura 1 - Resposta à questão 3 apresentada pelo aluno 27A

$$
\begin{aligned}
& \text { 3) Sim, pais de acondo com a esperno abarco, dechuzo ine sim } \\
& 7+21=28 / 31+7=38 \\
& q+11=20 \quad 21+5=24 \\
& 3+5=8 \quad 9+7=26 \\
& \begin{aligned}
3+3 & =8 \\
27+3 & =30 / 3+21 \\
3+7 & =28
\end{aligned}
\end{aligned}
$$

Fonte: Extrato do protocolo do aluno 27A.

Já 11 alunos apresentaram uma compreensão errônea do significado de demonstração, já que simplesmente repetiram a afirmação, como mostra a figura 2 : 


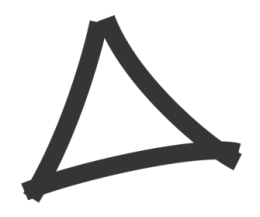

\section{Revista}

\section{Triângulo}

Figura 2 - Resposta à questão 3 apresentada pelo aluno $16 \mathrm{~A}$

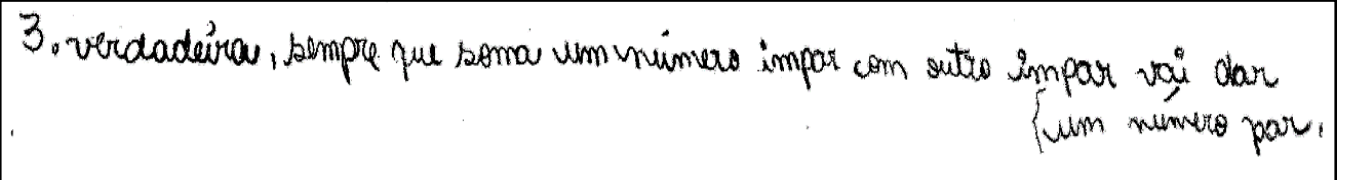

Fonte: Extrato do protocolo do aluno 16A.

Nestes casos, acreditamos que os alunos fizeram a operação mentalmente, e não se importaram em apresentá-la na resposta, optando por simplesmente reescrever a afirmação.

Quatro alunos responderam corretamente que a afirmação era verdadeira, porém cometeram algum erro na justificativa como, por exemplo, o aluno $33 \mathrm{~A}$ ao justificar que paridade do número está associada à regra de sinal da matemática, conforme mostra a figura 3:

Figura 3 - Resposta à questão 3 apresentada pelo aluno 33A

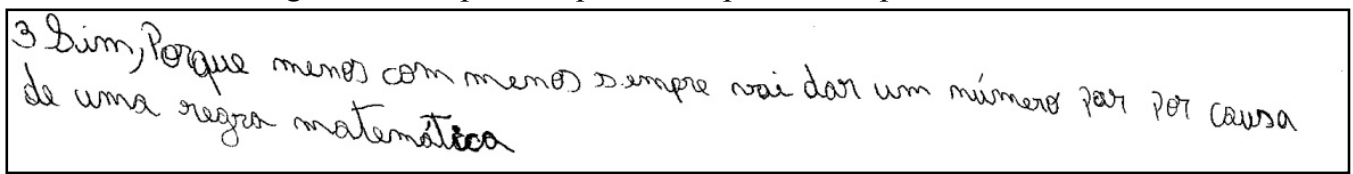

Fonte: Extrato do protocolo do aluno 33A.

Outros sete alunos não apresentaram nenhuma justificativa para a questão.

Com base na tabela 1, em ambas as turmas, a maior frequência em relação ao tipo de demonstração apresentada na questão 3 foi o empirismo ingênuo. No entanto, durante a análise das respostas dos alunos da turma $\mathrm{B}$, apareceram duas respostas que, segundo o referencial teórico, se enquadram na experiência crucial e no exemplo genérico, as quais são apresentadas nas figuras 4 e 5, respectivamente.

O aluno 24B observou que para o caso da soma de dois números ímpares iguais, é possível colocar em evidência o fator 2, pois trata-se do dobro deste número. Logo, o resultado sempre será um múltiplo de 2 , ou seja, par. No entanto, o discente não conseguiu generalizar este raciocínio para o caso da soma de dois números ímpares quaisquer.

Figura 4 - Resposta à questão 3 apresentada pelo aluno 24B

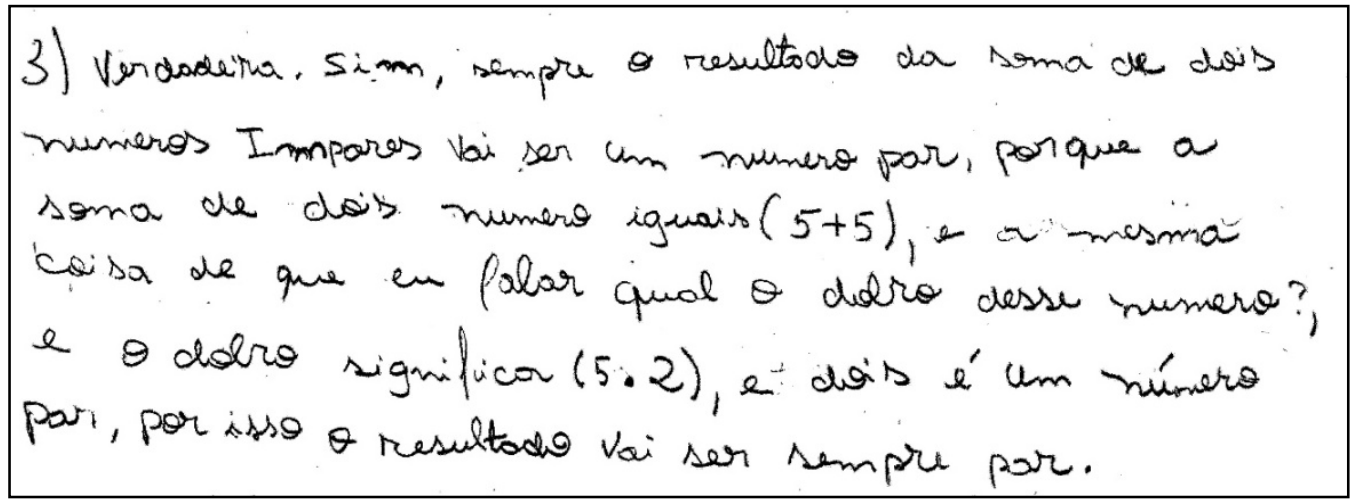

Fonte: Extrato do protocolo do aluno 24B. 


\section{$\Delta$}

\section{Revista}

\section{Triângulo}

Por este motivo, classificamos esta demonstração como experiência crucial, pois comprovou a hipótese mediante a verificação de um caso forte e particular, com evidências de generalização.

Figura 5 - Resposta à questão 3 apresentada pelo aluno 16B

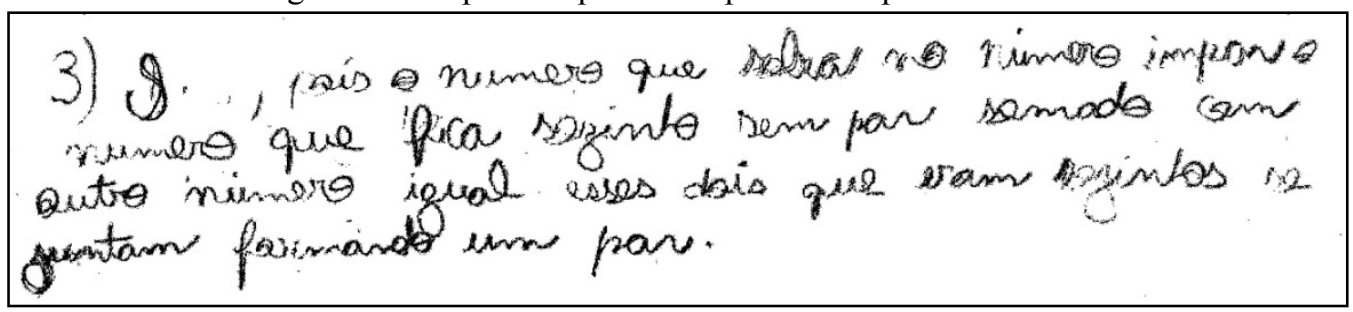

Fonte: Extrato do protocolo do aluno 16B.

Já o aluno 16B, embora não tenha escrito seu raciocínio utilizando a linguagem matemática, observou que dois números ímpares são da forma $2 \mathrm{k}_{1}+\mathrm{m}_{1}$ e $2 \mathrm{k}_{2}+\mathrm{m}_{2}$. Mesmo não concluindo que $\mathrm{m}_{1}=\mathrm{m}_{2}=1$, foi o único integrante da turma que relatou a possibilidade de escrever um número ímpar como uma soma de um número par com um "número que fica sozinho sem par". Por esta razão, classificamos a resposta apresentada como exemplo genérico, visto que esboçou um argumento, a fim de representar a classe de todos os exemplos possíveis que satisfazem a afirmação inicial.

$\mathrm{Na}$ questão 4, cujo objetivo era a generalização de raciocínio para o número de diagonais de um polígono convexo de $N$ lados, nenhum dos alunos conseguiu desenvolvê-la completamente.

Na turma A, apenas 20 alunos responderam corretamente ao item (a), poucos tentaram resolver o item (b) e no item (c), nenhum aluno desenvolveu alguma ideia para solucioná-lo. Logo, para analisar as respostas dos estudantes nos itens (b) e (c), investigamos os erros cometidos, a fim de compreender as razões que os levaram a não solucionar o problema ou a responderem incorretamente.

No item (b), nove alunos acertaram o número de diagonais de um hexágono convexo. Dos restantes, 26 erraram e um aluno não fez. Analisando as respostas, especialmente as ilustrações, percebemos que os participantes, em geral, não possuem conhecimentos geométricos consistentes para solucionar o problema, pois mesmo com a explicação e os exemplos do conceito de diagonal no início do teste, durante a aplicação houve vários questionamentos sobre o formato do hexágono convexo e sobre a definição de diagonal.

Já no item (c), 25 alunos não fizeram e oito responderam errado. Para o aluno 12A, o número de diagonais $D$ de um polígono de $N$ lados é dado pela expressão $D=\frac{N}{2}$, como mostra a figura 6. Observamos que este aluno não compreendeu o conceito de diagonal, pois no item (a), onde foi solicitada apenas a verificação de que o pentágono convexo possui 5 diagonais, ele afirma que "uma diagonal só é obtida entre 2 pontos". Consequentemente, a interpretação errônea de diagonal fez com que ele respondesse que o hexágono convexo 


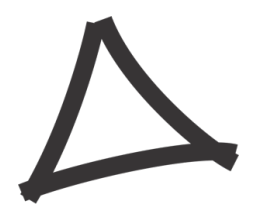

\section{Revista}

\section{Triângulo}

possui 3 diagonais e concluísse que o número de diagonais de um polígono convexo de $N$ lados é dado pela razão $\frac{\mathrm{N}}{2}$.

Figura 6 - Resposta à questão 4 apresentada pelo aluno 12A

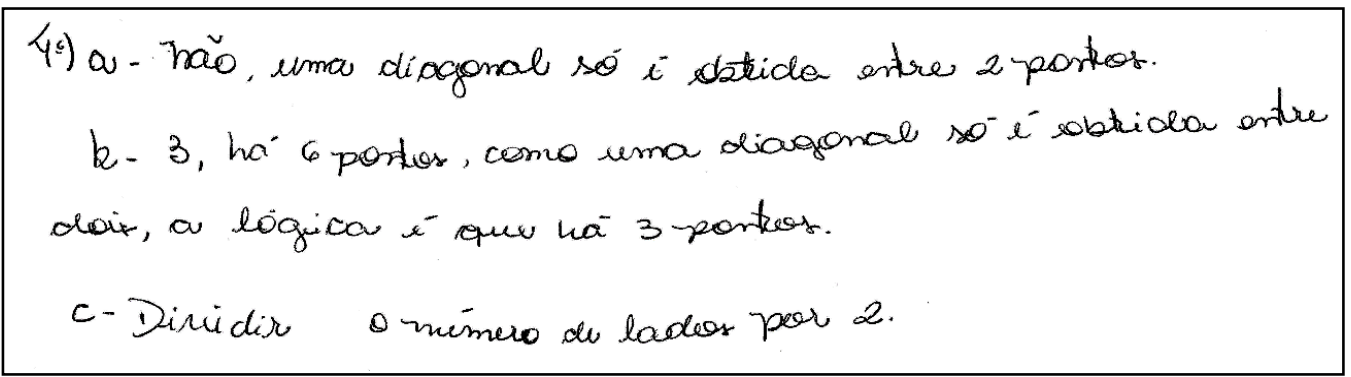

Fonte: Extrato do protocolo do aluno 12A.

$\mathrm{Na}$ turma $\mathrm{B}$, concluímos que, assim como aconteceu na turma $\mathrm{A}$, o não entendimento do conceito de diagonal ou a insuficiência de conhecimentos geométricos influenciaram na resolução do problema, visto que apenas 11 alunos conseguiram verificar que o número de diagonais de um pentágono convexo era 5. No item (b), apenas quatro alunos responderam corretamente, ao afirmar que um hexágono convexo possui 9 diagonais. Os demais erraram ou não responderam. E no item (c), também não houve alunos que souberam desenvolver alguma ideia para solucioná-lo.

Para concluir a análise da questão, três alunos da turma $\mathrm{A}$ e oito alunos da turma $\mathrm{B}$, ao responderem o item (b) e/ou (c), apresentaram um raciocínio de generalidade errôneo, corroborando a nossa hipótese para esse exercício. Esse fato é ilustrado pela resposta do aluno 9B, ao descrever que o número de lados $N$ e de diagonais $D$ em um polígono convexo são iguais para $N \geq 5$, já que para o triângulo $(N=3)$ e para o quadrado $(N=4)$, o enunciado do exercício informava o número de diagonais e ambos não satisfaziam esta relação, como mostra a figura 7 :

Figura 7 - Resposta à questão $4 \mathrm{~b}$ e $4 \mathrm{c}$ apresentada pelo aluno 9B

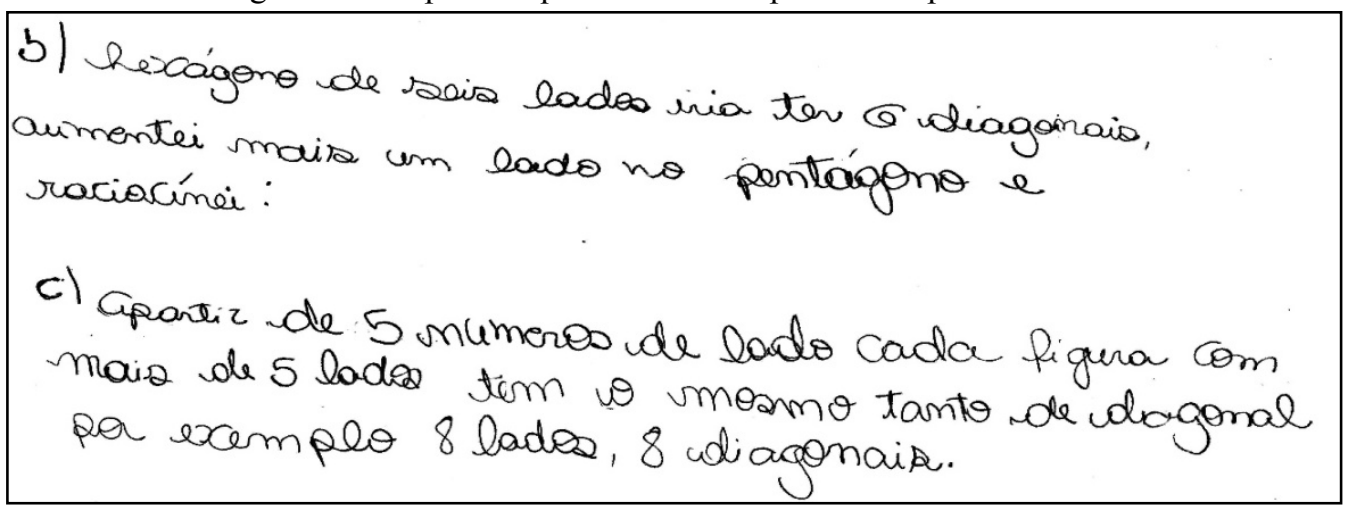

Fonte: Extrato do protocolo do aluno 9B.

Segundo Souza (2009), as causas dos erros cometidos e a raiz das dificuldades apresentadas pelos alunos nos problemas de demonstração são consequência da insuficiência

\begin{tabular}{l|l|l|l|l|l|l|} 
(C) Rev. Triang. & Uberaba, MG & v. 10 & n. 2 & p.74-93 & Jul.-Dez. 2017 & ISSN 2175-1609 \\
\hline
\end{tabular}




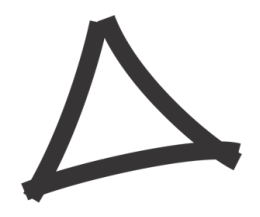

\section{Revista}

\section{Triângulo}

de conhecimentos elementares de Geometria Plana. Em nossa análise, comprovamos esse fato, pois além da ausência da habilidade de generalização por parte dos alunos, nenhum dos estudantes conseguiu encontrar a relação entre o número de lados e o número de diagonais de um polígono dado e escrever uma expressão para calcular o número de diagonais de um polígono convexo de $N$ lados.

É lamentável o fato de que a Geometria tem sido pouco trabalhada em sala de aula. A própria estrutura curricular da rede pública do Estado de São Paulo influencia para que isso ocorra, pois, em geral, os conteúdos geométricos são organizados para serem desenvolvidos no último bimestre do ano letivo. Porém, por fatores como a falta de tempo para abranger todo o currículo, os professores acabam não trabalhando esses tópicos com os alunos, o que dificulta o desenvolvimento da capacidade de visualização, da argumentação e a construção de demonstrações pelos alunos.

$\mathrm{Na}$ questão 6 foi solicitado que os alunos atribuíssem uma nota de 0 a 10 para as respostas da Amanda e do Breno, descritas na figura 8, ao problema de demonstrar a afirmação de que, em qualquer triângulo, a soma dos ângulos internos equivale a $180^{\circ}$. Além disto, era preciso justificar as notas atribuídas.

Figura 8 - Extrato da questão 6 do teste, com destaque para as respostas da Amanda e do Breno

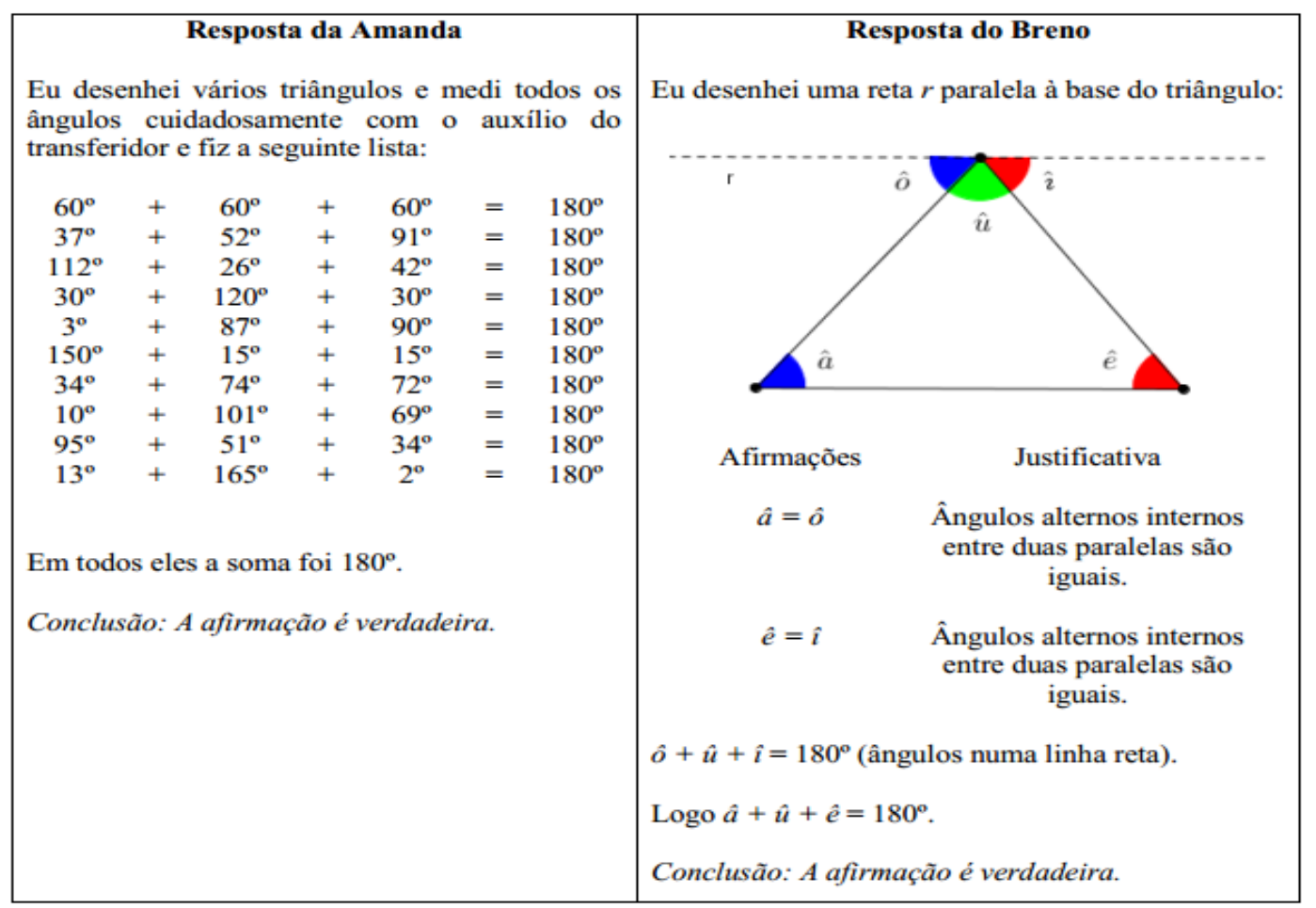

Fonte: Adaptado de Souza (2009).

Nas duas turmas, a resposta com maior frequência entre os alunos foi atribuir nota 10 para a Amanda e para o Breno e a justificativa pautava-se no fato de que ambos estavam corretos em relação ao raciocínio apresentado. No entanto, para o aluno 25A, a justificativa 


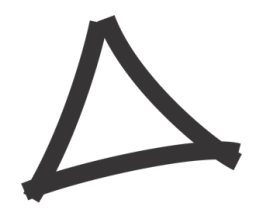

\section{Revista}

\section{Triângulo}

pelas duas notas 10 atribuídas consistia no fato de que Amanda utilizou cálculos matemáticos, e Breno mostrou na "prática". De modo geral, nas visões dos alunos não houve diferença entre as respostas apresentadas por Amanda e Breno. Entretanto houve alunos que atribuíram maior nota para a Amanda, devido ao fato de sua argumentação ser mais compreensível e completa, conforme a resposta do aluno 33A ilustrada na figura 9:

Figura 9 - Resposta à questão 6 apresentada pelo aluno 33A

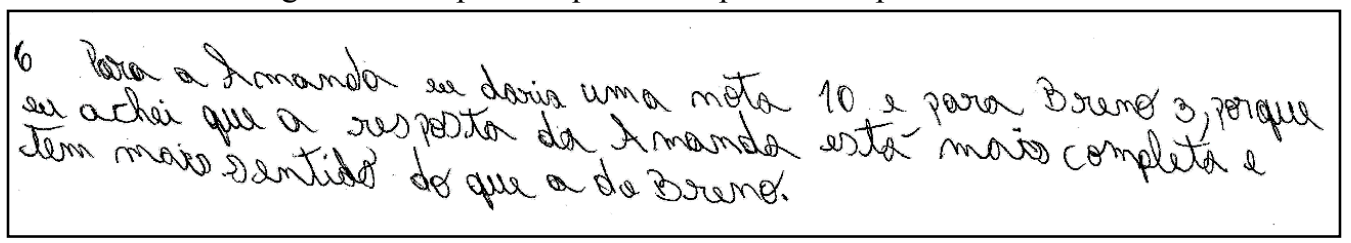

Fonte: Extrato do protocolo do aluno 33A.

Possivelmente por não ter entendido a argumentação apresentada pelo Breno, o aluno 33A atribuiu uma nota baixíssima a ele, ao contrário da nota 10 dada para a Amanda. Logo, podemos inferir que para esse aluno, uma demonstração consiste em uma verificação através de exemplos.

Já o aluno 1B justificou maior nota a Amanda devido ao maior número de verificações. Ou seja, para este aluno, quanto mais o aluno escreve, melhor é a resposta e, consequentemente, maior é a nota.

No entanto, também houve alunos que atribuíram maior nota ao Breno como, por exemplo, o aluno 21B, justificando que ele fez uma "conta" mais simples, diferentemente da Amanda que mediu todos os ângulos, conforme relata em sua resposta retratada na figura 10:

Figura 10 - Resposta à questão 6 apresentada pelo aluno 21B

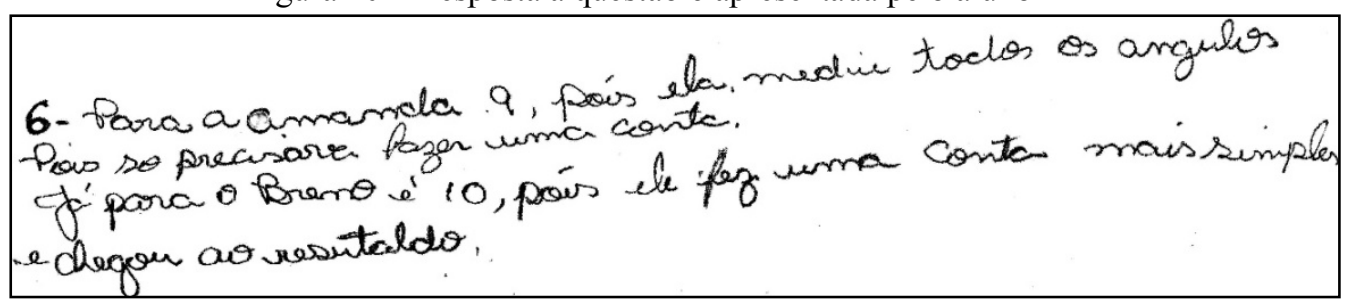

Fonte: Extrato do protocolo do aluno 21B.

Ou ainda, como o aluno 17A, que justificou a nota atribuída pelo fato de que a explicação de Breno foi mais extensa e completa, conforme mostra a figura 11:

Figura 11 - Resposta à questão 6 apresentada pelo aluno 17A

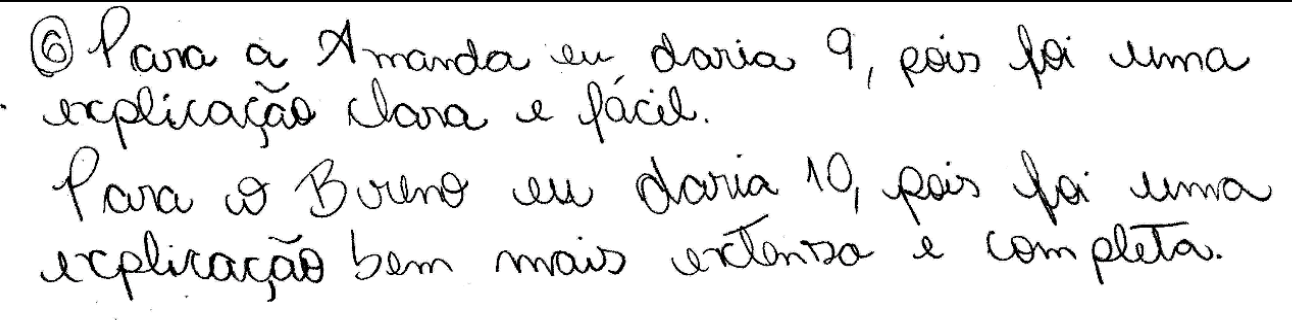




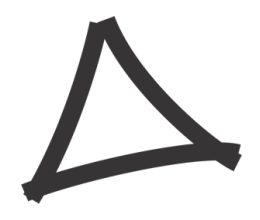

Revista

Triângulo

Fonte: Extrato do protocolo do aluno 17A.

Ao analisar as respostas dos alunos das turmas A e B, observamos que nenhum aluno mencionou o fato de que, embora Amanda esteja correta nos cálculos, a lista que ela apresenta não abrange todos os casos possíveis e isto não caracteriza uma demonstração. Ao contrário, Breno, com o uso do conhecimento geométrico, demonstra a veracidade da afirmação para qualquer triângulo. Portanto, podemos inferir que para os alunos das turmas A e B o conceito de verificação e de demonstração são interpretados como sinônimos, não observando diferença entre o nível de empirismo ingênuo (resposta da Amanda) e o nível de experiência mental (resposta do Breno).

\section{CONSIDERAÇÕES FINAIS}

O estudo apresentado neste artigo investigou as visões de professores e alunos do Ensino Fundamental sobre argumentação e demonstração matemática.

Verificamos que todos os professores participantes afirmaram que receberam estímulo total ou parcial à prática voltada ao ensino-aprendizagem de prova/demonstração durante a sua formação. No entanto, ao analisar qualitativamente as questões sobre os entendimentos dos docentes, para cerca de metade deles, notamos que os termos argumentação, explicação e demonstração são assimilados como sinônimos em sala de aula.

Constatamos que os docentes que apresentavam entendimentos sobre os termos argumentação, prova e demonstração próximas às definições apresentadas por Balacheff (1987) cursaram a graduação em instituições públicas. No entanto, destacamos que não basta apenas conhecer a definição destes termos, é preciso que os cursos de licenciatura em matemática das instituições públicas e particulares proporcionem aos futuros professores a oportunidade de conceber a argumentação e demonstração como um recurso metodológico a ser utilizado em sala de aula, a fim de criar um ambiente favorável à exploração e investigação da matemática, conforme evidenciam Fiorentini e Oliveira:

[...] não é suficiente o futuro professor conhecer teoricamente, ou a partir da didática da matemática, como podem ser e funcionar as demonstrações em um ambiente exploratório-investigativo com a matemática. É preciso que ele possa experienciar o processo de exploração e investigação nas disciplinas matemáticas da licenciatura, tais como: teoria dos números, cálculo diferencial e integral, álgebra, análise, geometria, fractais, teoria dos grafos etc (FIORENTINI; OLIVEIRA, 2013, p. 925).

Nossos dados destacam ainda, a influência social no processo de formação das visões de um indivíduo. Ao observar que os professores concebem os termos argumentação, explicação e demonstração como sinônimos, inferimos que eles influenciam também as compreensões dos seus alunos em relação a essas terminologias. Constatamos esse fato, por exemplo, na questão 6 do teste, onde os conceitos de verificação e de demonstração foram interpretados como sinônimos pelos alunos ao atribuírem notas semelhantes para a Amanda 


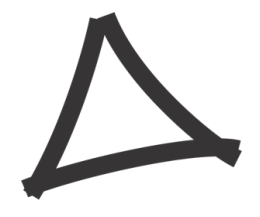

Revista

Triângulo

(nível de empirismo ingênuo, caracterizando uma verificação) e para o Breno (nível de experiência mental, caracterizando uma demonstração).

O fato de os alunos não compreenderem o significado de demonstração e interpretarem os termos apresentados neste estudo como sinônimos parece confirmar uma consideração feita por Aguilar Junior (2012), de que o ensino de prova não faz parte da prática pedagógica da maioria dos professores da Escola Básica. Além disso, verificou-se a predominância do empirismo ingênuo nas justificativas dos discentes, corroborando as considerações apresentados nos estudos de Souza (2009) e Aguilar Junior (2012).

Inicialmente a nossa conjectura era de que professores que declarassem o uso do recurso metodológico voltado ao ensino de argumentação e provas em sala de aula usassem práticas pedagógicas que possibilitariam desenvolver em seus alunos reflexões, intuições, níveis de prova mais elevados do que os professores que simplesmente afirmaram que não fazem uso de tais práticas. Logo, a expectativa era que a turma A apresentasse um desempenho melhor em relação à turma $\mathrm{B}$, já que o professor $\mathrm{P} 8$ afirmou que usava esse recurso metodológico e que não encontrava dificuldades ao utilizá-lo, ao contrário do professor P2. Entretanto, a análise dos dados evidenciou que ambas as turmas apresentaram resultados muito semelhantes.

Na realidade, com base na questão 3 do teste, na turma B tivemos duas respostas que se destacaram, ao conter justificativas que, segundo a tipologia de provas, se enquadram no nível da experiência crucial e do exemplo genérico. Entretanto, por se tratar de apenas duas respostas isoladas numa turma de 28 alunos, não podemos tomá-las como representantes deste grupo e inferir que o desempenho da turma $\mathrm{B}$ foi melhor em relação à turma $\mathrm{A}$. Além disso, nossa análise não se limita apenas a uma determinada questão, mas sim na investigação do teste em sua totalidade. Logo, o que podemos afirmar é que não houve significativas diferenças no desempenho dos alunos de ambas as turmas.

De acordo com Balacheff (1988), para que o aluno possa compreender o significado e desenvolver uma demonstração, é preciso que ele atinja o quarto nível, classificado como experiência mental.

Diante deste contexto, um questionamento torna-se inevitável: se nos alunos que cursam o $9^{\circ}$ ano do Ensino Fundamental, que marca a transição do Ensino Fundamental para o Médio, predominou o empirismo ingênuo em suas justificativas, que consiste no primeiro nível de prova da teoria de Balacheff, é possível que no Ensino Médio estes alunos alcancem o quarto e último nível?

Acreditamos que não, já que no Ensino Médio o foco está voltado para os conteúdos que são cobrados nos vestibulares e concursos. Como as questões relacionadas à argumentação e demonstração matemática não são abordadas nesses exames e geralmente nem nas avaliações escolares, os alunos não se sentem motivados a aprender com a utilização deste recurso metodológico. Além disso, quando raramente é utilizado em sala, tende a ser

\begin{tabular}{l|l|l|l|l|l|l|} 
(C) Rev. Triang. & Uberaba, MG & v. 10 & n. 2 & p.74-93 & Jul.-Dez. 2017 & ISSN 2175-1609 \\
\hline
\end{tabular}




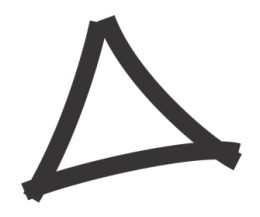

Revista

Triângulo

interpretado pelos discentes como uma mera curiosidade ou como um conhecimento que não favorece a aprendizagem.

Este fato é reforçado pela resposta apresentada no questionário pelo professor P6, que diz:

“(...) durante o processo de justificativa a indisciplina se instala e até mesmo os que acompanhavam o raciocínio imprimido pelo professor, também se perdem. É comum a pergunta: 'isto cai na prova?'. O imediatismo leva o aluno a buscar o uso de maquinal ${ }^{1}$ dos resultados."

Deste modo, parece que a formação do aluno na Educação Básica não garante que ele atinja o nível de prova intelectual e, consequentemente, este aluno não estará apto a dominar a capacidade de argumentar e demonstrar os conteúdos matemáticos, conforme orientam os Parâmetros Curriculares Nacionais (BRASIL, 1998) e a Base Nacional Comum Curricular (BRASIL, 2017). Além disso, em consonância com o professor P6, a ausência da metodologia referente à argumentação e demonstração em sala de aula faz com que esse aluno perca o "lado da matemática que talvez o levasse mais longe, preparando-o com melhor qualidade para os desafios da própria vida".

\section{REFERÊNCIAS}

AGUILAR JUNIOR, C. A. Postura de docentes quanto aos tipos de argumentação e prova matemática apresentados por alunos do ensino fundamental. 2012. $144 \mathrm{f}$. Dissertação de Mestrado em Ensino de Matemática - Universidade Federal do Rio de Janeiro. Rio de Janeiro, 2012.

BALACHEFF, N. Processus de preuve et situations de validation. Educational Studies in Mathematics, v. 18, n. 2, p. 147-176, 1987.

Aspects of proof in pupil's practice of school mathematics. In: D. PIMM (ed.). Mathematics teachers and children. London: Hodder and Stoughton, 1988, p. 216-235.

BRASIL. Secretaria de Educação Média e Tecnológica. Parâmetros curriculares nacionais: Ensino Médio. Brasília: MEC/SEF, 1998. Disponível em: $<$ http://portal.mec.gov.br/seb/arquivos/pdf/ciencian.pdf $>$. Acesso em: 31 jan. 2018.

Ministério da Educação. Base Nacional Comum Curricular: educação é a base. $3^{\mathrm{a}}$ versão. Brasília: MEC/CONSED/UNDIME, 2017. Disponível em: $<$ http://basenacionalcomum.mec.gov.br/images/BNCC_20dez_site.pdf $>$. Acesso em: 31 jan. 2018 .

\footnotetext{
${ }^{1}$ Como o professor P6 não esclarece o significado do termo maquinal em sua resposta, através do contexto das ideias apresentadas pelo docente, acreditamos que pode ser entendido como o uso de fórmulas prontas ou de procedimentos que são simplesmente memorizados.
} 


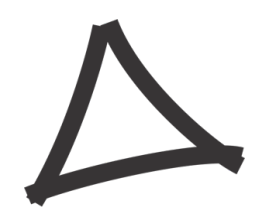

Revista

\section{Triângulo}

FIORENTINI, D.; OLIVEIRA, A. T. O lugar das matemáticas na licenciatura em Matemática: que matemáticas e que práticas formativas? Bolema, v. 27, n. 47, p. 917-938, 2013.

GARNICA, A. V. M. As demonstrações em educação matemática: Um ensaio. Bolema, v. 15, n. 18, p. 91-99, 2012.

GRAVINA, M. A. Os ambientes de geometria dinâmica e o pensamento hipotético dedutivo. 2001. 277 f. Tese de Doutorado em Informática na Educação - Universidade Federal do Rio Grande do Sul. Porto Alegre: 2001.

MATEUS, M. E. A. Um estudo sobre os conhecimentos necessários ao professor de Matemática para a exploração de noções concernentes às demonstrações e provas na Educação Básica. 2015. 269 f. Tese de Doutorado em Educação Matemática - Universidade Anhanguera de São Paulo. São Paulo: 2015.

NASSER, L.; TINOCO, L. A. A. Argumentação e provas no ensino de Matemática. 2 ed. Rio de Janeiro: UFRJ/Projeto Fundão, 2003. 109 p.

NUNES, J. M. V.; ALMOUlOUD, S. A. Argumentação no ensino de Matemática: perspectivas metodológicas. REMATEC, n. 13, p. 145-169, 2013.

ORDEM, J. Prova e demonstração em geometria plana: concepções de estudantes da licenciatura em ensino de Matemática em Moçambique. 2015. 341 f. Tese de Doutorado em Educação Matemática - Pontifícia Universidade Católica de São Paulo. São Paulo, 2015.

PIETROPAOLO, R. C. (Re) significar a demonstração nos currículos da educação básica e da formação de professores de Matemática. 2005. $388 \mathrm{f}$. Tese de Doutorado em Educação Matemática - Pontifícia Universidade Católica de São Paulo. São Paulo, 2005.

SOUZA, M. E. C. O. A questão da argumentação e prova na matemática escolar: o caso da medida da soma dos ângulos internos de um quadrilátero qualquer. 2009. $115 \mathrm{f}$. Dissertação de Mestrado Profissional em Ensino de Matemática - Pontifícia Universidade Católica de São Paulo. São Paulo, 2009. 